\title{
Cytokines profiles in intestinal epithelial (Caco-2) cells exposed to 7-ketostigmasterol or 7-ketocholesterol
}

\author{
L. Alemany ${ }^{1}$, J. M. Laparra ${ }^{2}$, R. Barberá ${ }^{1}$ and A. Alegría ${ }^{1}$ \\ ${ }^{1}$ Nutrition and Food Chemistry. Faculty of Pharmacy, University of Valencia, Avda. Vicente Andrés Estellés s/n, 46100 \\ Burjassot, Spain and ${ }^{2}$ Agrochemistry and Food Technology Institute, National Research Council, Avda. Agustin Escardino \\ 7, 46980 Paterna, Spain
}

Plant sterols (PS) exert hypocholesterolemic effects and prevent cardiovascular diseases. In addition, PS have evidenced immunomodulatory properties promoting anti-inflammatory ${ }^{(1)}$ and both innate and adaptive immune response(s) ${ }^{(2)}$. It is known that PS are susceptible to oxidation increasing their cytotoxicity; however, the influence of oxidized derivatives on inflammation and immune response(s) has been poorly evaluated and, in in vitro models, only in monocytic (U937) cells ${ }^{(3)}$. The objective of the present study was to compare cytokine profiles in intestinal epithelial (Caco-2) cells exposed to 7-ketostigmasterol and 7-ketocholesterol. Caco-2 cell cultures (initial density of 50.000 cells $\left./ \mathrm{cm}^{2}\right)$ were challenged $(5$ days post-seeding) to solutions $(60 \mu \mathrm{M})$ of 7-ketostigmasterol or 7-ketocholesterol for $3 \mathrm{~h}$. Relative changes in the expression (mRNA) of IL-1 $\beta$ receptor, TNF- $\alpha$ and NFKB (p65) were monitored by reverse transcription-qPCR, and interleukin (IL)-8 and IL-10 production were quantified by ELISA. Cell cultures exposed to 7-ketostigmasterol exhibited a sharp upregulated expression of IL-1 $\beta$ receptor, TNF- $\alpha$ and NFKB (Fig. 1A). This cellular response(s) was accompanied of a marked increase in IL-8, but slight IL-10, production (Fig 1B). These results indicate potential negative alterations in intestinal permeability favoring the interaction with intraepithelial lymphocytes. 7-ketocholesterol only induced a moderate up-regulation of IL-1 $\beta$ receptor and significant lower concentrations of IL-8 than 7-ketostigmasterol.
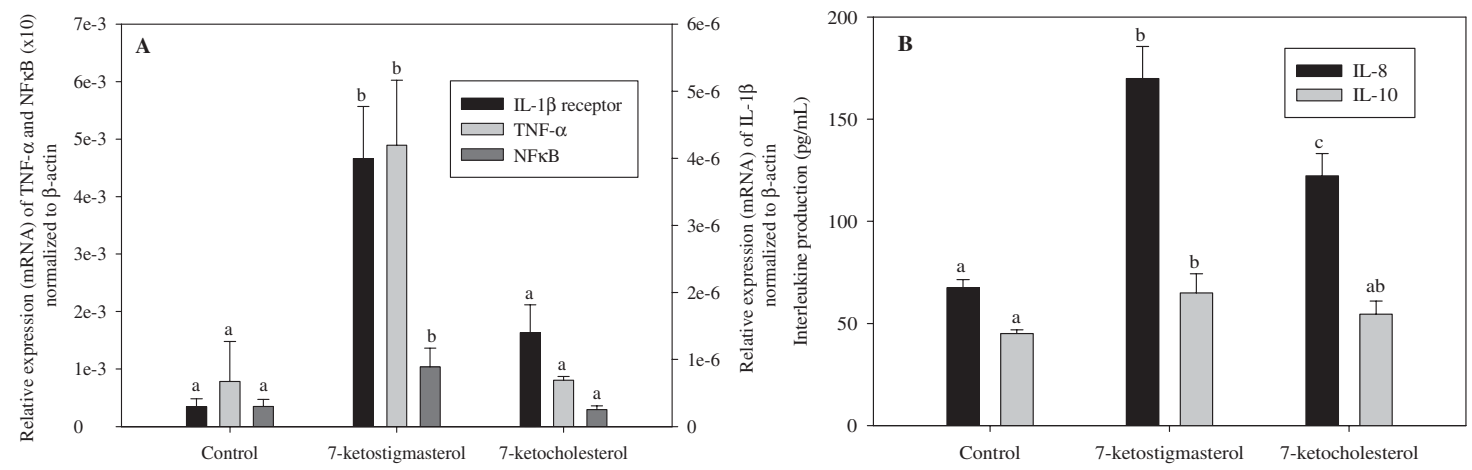

Figure 1. Changes in IL-1 $\beta$, TNF- $\alpha$ and NFאB expression (A) and IL-8 and IL-10 production (B) (Mean \pm SD, $n=4)$.

The results evidenced that 7-ketostigmasterol caused more severe inflammatory response(s) than 7-ketocholesterol to Caco-2 cells cultures. The potential negative impact of $7 \mathrm{k}$-stigmasterol on intestinal epithelium integrity could alter its morphological functionality.

1. Othman RA \& Moghadasian MH (2011) Nutr Rev 69 (7), 371-382.

2. Brüll F, Mensink RP, van den Hurk K, Duijvestijn A \& Plat J (2010) J Biol Chem 29, 285(5): 2951-2958.

3. Vejux A, Montange T, Martine L et al. (2012) J Agr Food Chem 60, 4060-4066. 